\title{
DEVELOPING INNOVATIVE STRATEGIES FOR MULTICULTURAL COMMUNICATION
}

Terry Chesher and Michelle Young

NSW Multicultural Health Communication Service

This article describes the development of the NSW Multicultural Health Communication Service (Multicultural Communication) since its creation in 1997. The development and rationale of the service are described, as are its goals and core functions.

\section{HOWTHE SERVICE HAS DEVELOPED}

For a number of years the NSW Department of Health produced and distributed multilingual health information through the former Health Translation Service. In 1997 Multicultural Communication was established as a statewide service whose mandate includes the multilingual aspects of all health communication. It is funded by the Multicultural Health Branch and Health Promotion Branch of the NSW Department of Health, and is based in the South Eastern Sydney Area Health Service.

In the first triennium following its inauguration, Multicultural Communication has focused on establishing processes, systems and a strong knowledge base to enable capacity-building throughout the NSW Health system for the communication of information about health and health services to people of culturally and linguistically diverse (CALD) backgrounds. This has been assisted by a management committee-with representation from the NSW Department of Health, the South Eastern Sydney Area Health Service, and the Area-based Multicultural Coordinators - and by advisory committees. These management and advisory committees oversee the effective dissemination of multilingual resources.

Multicultural Communication supports the NSW Department of Health by:

- ensuring that statewide campaigns are tailored to reach speakers of languages other than English;

- providing expert advice on the development of communication strategies for CALD communities;

- implementing those strategies through campaigns when required, for example: tobacco cessation, physical activity, food safety, and nursing recruitment.

From the outset there has been strong demand for research and marketing services in public health initiatives for CALD communities. In response to this demand Multicultural Communication has developed a consultancy role to the area health services, other health outlets, and non-government organisations, to facilitate and evaluate cross-cultural communication.

\section{RATIONALE OF THE SERVICE}

In recognition of the heterogeneity of the CALD communities in NSW, Multicultural Communication was set out by the NSW Department of Health as part of its commitment to the principles of access and equity. According to the 1996 Census of the Population of NSW:

- 15.8 per cent were born in a non-English speaking country

- 17 per cent speak a language other than English

- 3.8 per cent have a low proficiency in English or do not speak English at all.

Immigrants of non-English speaking backgrounds face many linguistic and cultural barriers when trying to utilise health services. Lack of proficiency in English is a major contributing factor to low health literacy. 'Health literacy represents the cognitive and social skills which determine the motivation and ability of individuals to gain access to, understand and use information in ways which promote and maintain good health.' ${ }^{1}$ Studies in Australia and overseas have identified low health literacy as a risk factor for poor health outcomes and a poor understanding of preventive health practices (for example, the cessation of smoking). ${ }^{2}$ Higher rates of inappropriate use of health services are also associated with low health literacy.

\section{GOALS OFTHE SERVICE}

The goals of Multicultural Communication are to:

- improve the quality of communication between the health system and communities from CALD backgrounds;

- provide advice to the health system on effective communication strategies;

- provide a central point for the collection and exchange of knowledge about multicultural communication.

In its policy advice and development role, Multicultural Communication strives to raise awareness and implement the principles of, the State government's Charter of Principles for a Culturally Diverse Society, through identifying and addressing barriers to access by CALD communities to health information and services. For example, having identified that due to a lack of awareness the production of new resources was being duplicated by area health services, a new policy document entitled Standard Procedures for Areas Developing Multilingual Resources was produced for dissemination throughout the health system. A protocol to ensure currency of all multilingual publications has also been promulgated. To support these policies, guidelines on producing multilingual resources and on checking translations, have also been produced and are available both in hard copy and on the Multicultural Service's Web site.

Multicultural Communication performs an advisory role to NSW Health, maintaining close contact with coordinatiors in Areas who have responsibility for multicultural health. Through this network Multicultural 


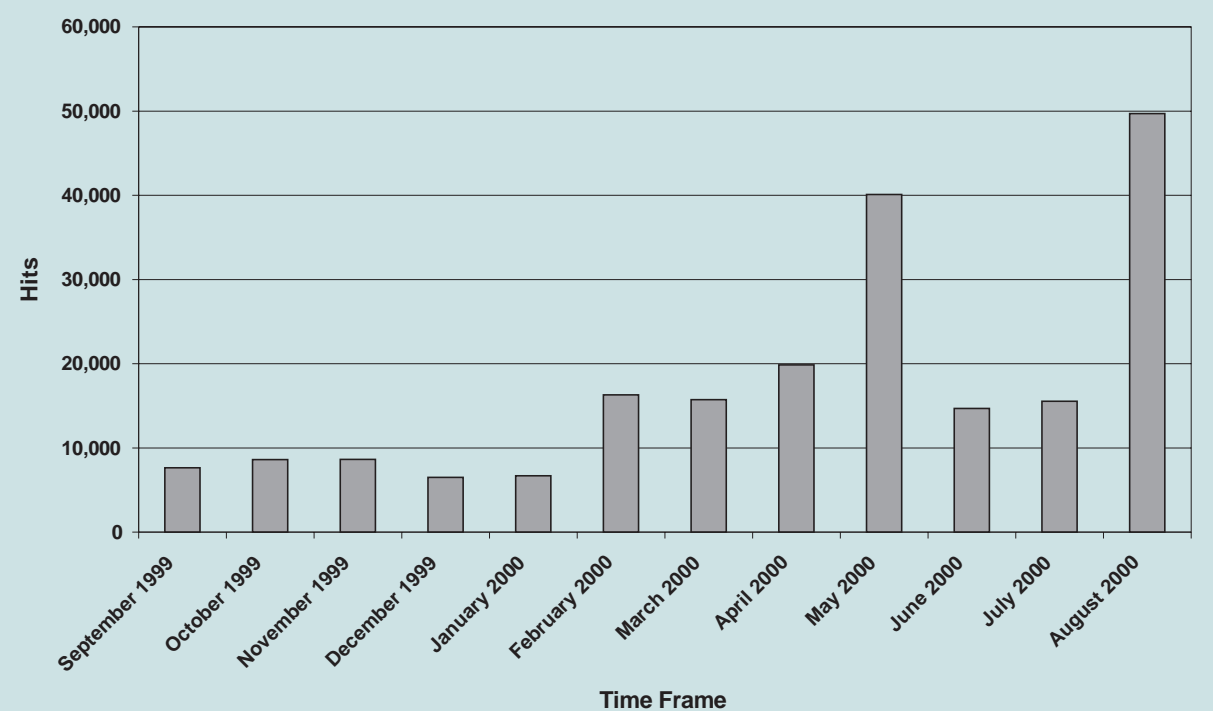

Communication provides advice on the communication needs of CALD communities, including the particular need for new multilingual information. An annual survey is conducted in conjunction with the collection of data for the Ethnic Affairs Priority Statement, in which the area health services are asked to report on:

- new resources they have produced

- resources 'in the pipeline'

- priorities for the production of new multilingual health resources.

The service has also provided advice on the translation and/or production of various resources. For example, Multicultural Communication worked with the Epidemiology and Surveillance Branch of the NSW Department of Health on the translation and adaptation of the NSW Health Survey to languages other than English.

\section{RESEARCH ACTIVITIES}

Multicultural Communication is committed to practices that are informed by evidence-based research and the sharing of knowledge. Examples include:

- market research with Arabic and Khmer speakers to establish media preferences within the community; ${ }^{3,4}$

- management of a survey to evaluate a resource produced by the Central Sydney Area Health Service for Chinese-speaking migrants designed to improve knowledge in that population of important health issues and of the NSW Health System;

- research with communities in South Western Sydney to assist with the development of new service delivery models for CALD communities in the Families First Multicultural Project. ${ }^{5}$

\section{INFORMATION SERVICES}

To meet the challenge of ensuring access to health information and services for CALD communities, Multicultural Communication has invested in a range of strategies to ensure that the available resources are better known and accessible to all parts of the health system.

\section{Web site}

Multicultural Communication's multilingual Web site was developed and launched in 1997. That same year the Web site won the Australian Financial Review-Telstra Australian Internet Award for the best professional services site. The Web site contains:

- multilingual health information

- an online catalogue called Catalogue Online

- a directory of multicultural health promotion projects and research (which health staff can add to by completing and forwarding forms online)

- a searchable catalogue of ethnic media (television, radio and print)

- Guidelines for health staff producing multilingual information

- Seven Steps: guidelines for health staff checking translations

- Strategic Plan (1999-2002)

- news, including copies of the quarterly newsletter Polyglot.

The online catalogue lists all available publications accessible through the Web site and is continually updated as new material is uploaded. Over 400 publications in up to 35 languages can be downloaded directly from the Web site by health staff. 
Figure 1 shows the number of visits to the Web site over the last 12 months. The number of visits has increased over a 12 month period. However it should be noted that over the first three years, the number of publications downloaded in English far exceeded the quantity accessed in other languages. This may indicate that employees of NSW Health are not aware that they can download from the Web site any publication in any language, without the need for special software.

Multicultural Communication promotes its Web site as the preferred distribution mechanism of multilingual information. However, printed resources are also distributed and promoted through each area health service for those without internet or intranet access.

\section{Facsimile service}

For the benefit of NSW Health staff without access to the intranet or internet, multilingual information will shortly be provided via the Health Faxback Service. For the cost of a local call the Health Faxback Catalogue is faxed to users, who can use a touchtone phone to order copies of publications which are then faxed back to them in the languages they select.

\section{Ethnic press service}

In 1997 Multicultural Communication assumed management of an existing program, the Health Column project, which involved publication of articles on a weekly basis in the ethnic press in 16 community languages. Research with the Arabic and Khmer communities suggested the need to move the Health Columns project from its previous media focus on the ethnic press to a greater emphasis on other printed publications as a tool for health staff working with CALD communities. ${ }^{3}$

\section{Radio service}

Access to information is a high priority for all CALD communities, but particularly for newly arrived groups. This can be enhanced through broadcasting on ethnic radio. Radio health segments for new arrivals were developed in conjunction with the NSW Refugee Health Service's Health Information Program for Bosnian and Somali audiences. The purpose was to extend the reach of that program across NSW, particularly to listeners who traditionally rely on oral communication.

\section{Marketing and communication campaigns}

Social marketing and communication campaigns are arranged for public health issues, using research to identify the specific areas of need within a community and developing ethno-specific messages and communication strategies. The service has developed successful social marketing campaigns in areas such as smoke alarms, ${ }^{6}$ as well as the Multilingual Communication Campaign for the NSW Cervical Screening Program (1999). These projects, along with other statewide campaigns undertaken for NSW Health, have involved provision of media training to bilingual workers, thus building a network of skilled communicators on which the health system can draw.

\section{FUTURE DIRECTIONS}

As Multicultural Communication moves into its fourth year, a new Strategic Plan has been developed, following recommendations from an independent review of the Service. Membership of the Management Committee has been reviewed, and advisory committees amalgamated. Due to proposed building alterations on the Royal South Sydney Community Health Complex site, Multicultural Communication was relocated in August 2000 to new premises at Sydney Hospital and Sydney Eye Hospital.

\section{REFERENCES}

1. World Health Organization. Health Promotion Glossary. New York: WHO, 1998.

2. Williams, MV et al. Relationship of functional health literacy to patients' knowledge of their chronic disease: a study of patients with hypertension and diabetes. Arch Intern Med 1998; 158 (2): 166-172.

3. Sources of health information for Khmer speakers in NSW: an evaluation of the Health Column in the Khmer press. Sydney: NSW Multicultural Health Communication Service, 1999.

4. Sources of health information for Arabic speakers in NSW: an evaluation of the Health Column in the Arabic press. Sydney: NSW Multicultural Health Communication Service, 1999.

5. Hudson D. Progress on Families First: a support network for families raising children. NSW Public Health Bulletin 2000; Vol. 11 No. 5: 77-79.

6. Young, M, Camit M and Mihajlovic M. A smoke alarm campaign in Arabic, Chinese and Vietnamese communities. NSW Public Health Bulletin 1999; Vol. 10, No. 10: 133135.

Further information about the services provided by Multicultural Communication can be obtained from NSW Multicultural Health Communication Service, Level 1, North Block, Sydney Hospital and Sydney Eye Hospital, Macquarie Street, Sydney NSW 2000. Postal address: GPO Box 1614, Sydney NSW 2001; email address:mhcs@sesahs.nsw.gov.au; telephone: (02) 9382 7516; facsimile: (02) 93827517 ; Faxback Service: 1300859659.

The Multicultural Communication Web site can be accessed via the internet at HealthWeb:

www.mhcs.health.nsw.gov.au, or via the intranet at HealthNet: internal.health.nsw.gov.au/healthpublic-affairs/mhcs. 